\title{
Effects of statewide health promotion in primary schools on children's sick days, visits to a physician and parental absence from work: a cluster-randomized trial
}

\author{
Dorothea Kesztyüs ${ }^{1,2^{*}} \mathbb{D}$, Romy Lauer ${ }^{1}$, Meike Traub ${ }^{1}$, Tibor Kesztyüs ${ }^{3}$ and Jürgen Michael Steinacker ${ }^{1}$
}

\begin{abstract}
Background: Based on the World Health Organization's global school health initiative we investigate intervention effects of statewide health promotion in schools on the numbers of children's sick days and visits to a physician, and parental days off work due to child illness.

Methods: Cluster-randomized trial with 1-year follow-up in primary schools in the state of Baden-Württemberg, Germany. Anthropometric measurements of first and second grade school children were taken by trained staff. Parents filled in questionnaires for information about socio-demographics, health-related variables, numbers of children's sick days, visits to a physician, and days parents had to stay off work to care for a sick child. Longitudinal differences in the outcome variables were calculated between baseline and follow-up. Intraclass correlation coefficients were determined to quantify a possible clustering of data in schools. Accordingly, linear models and linear mixed models were applied to identify relationships and ascertain significances.
\end{abstract}

Results: Data from 1943 children ( $1^{\text {st }}$ grade $n=1024,6.6 \pm 0.4$ years old; $2^{\text {nd }}$ grade $n=919,7.6 \pm 0.4$ years old $)$ were available at baseline. Unadjusted differences regarding both grades were found between mean longitudinal changes in intervention and control group in children's sick days ( $-3.2 \pm 7.1$ vs. $-2.3 \pm 5.6, p=0.013)$, and maternal days off work ( $-0.9 \pm 2.4$ vs. $-0.5 \pm 2.8, p=0.019$ ). The intervention effect on sick days was adjusted in a linear regression for baseline values, gender and migration background and confirmed for first grade children $(B=-0.83, p=0.003)$. The intervention effect on maternal days off work lost its significance after adjusting for baseline values. No significant differences were detected in the numbers of children's visits to a physician and paternal days off work.

Conclusions: School-based health promotion slightly reduces sick days in first grade children. Subsequently, parents may not need to stay off work themselves. Small individual effects add up to larger benefits in a statewide implementation of health promotion. Additionally, health promotion may also positively contribute to school success.

Trial Registration: The study was registered on the German Clinical Trials Register (DRKS), Freiburg University, Germany, under the DRKS-ID: DRKS00000494. Registered: 25 August 2010.

Keywords: Sick leave, Child, Schools, Health promotion, Physicians, Utilization, Parents

\footnotetext{
*Correspondence: dorothea.kesztyues@uni-ulm.de

1 Division of Sport and Rehabilitation Medicine, Ulm University Medical

Center, 89075 Ulm, Germany

2Ulm University, Institute of General Medicine, Helmholtzstraße 20, D-89081

Ulm, Germany

Full list of author information is available at the end of the article
}

\section{) Biomed Central}

(c) The Author(s). 2016 Open Access This article is distributed under the terms of the Creative Commons Attribution 4.0 International License (http://creativecommons.org/licenses/by/4.0/), which permits unrestricted use, distribution, and reproduction in any medium, provided you give appropriate credit to the original author(s) and the source, provide a link to the Creative Commons license, and indicate if changes were made. The Creative Commons Public Domain Dedication waiver (http://creativecommons.org/publicdomain/zero/1.0/) applies to the data made available in this article, unless otherwise stated. 


\section{Background}

In 1995 the World Health Organisation (WHO) launched the global school health initiative to mobilise and strengthen health promotion and education activities at the local, national, regional and global levels [1]. In their subsequent report on the effectiveness of health promotion in schools in 2006, the WHO identified programmes that promote mental health, healthy eating, and physical activity as being amongst the most effective [2]. They detected that most interventions used classroom-only approaches, and some combined a curriculum approach with environmental changes or family involvement [2]. Combined approaches were more likely to be successful, but many interventions appeared to be ineffective [2]. None of the reviews included in the WHO report provided information on the costs, or cost-effectiveness, of health promotion programmes in schools [2]. However, due to a large amount of existing interventions but limited (financial) resources, cost-effectiveness analyses are essential. For such analyses, direct and indirect costs have to be assessed, and the numbers of visits to a physician or productivity losses due to parental absence from work because they have to care for a sick child are important parts of it.

Only recently, we determined the cost-effectiveness of school-based health promotion in terms of averted cases of incidental abdominal obesity as a result of the BadenWürttemberg Study (unpublished data). A crosssectional analysis of the baseline data of this study also showed that abdominal obesity in primary schoolchildren was associated with higher rates of children's sick days and more visits to a physician [3]. We use the term sick days for the findings, because absenteeism may have a broader meaning beyond sickness; even though absenteeism and sick leave in the context of school children is used interchangeably by many authors. While school absenteeism has been studied elsewhere from different perspectives [4], information about health-related absenteeism in primary school children is limited. Some authors found associations of body mass index and obesity with school absenteeism, but results are not consistent [5-10]. In a Dutch population sample of 3960 8-year-old children, obesity was associated with significantly more school absenteeism [5]. In contrast, data from 920 fourth grade children in the United States (US) did not show a significant relationship between the number of school days absent for each child and the BMI percentile category [6]. Another study from the US examined more than 165,000 students in grades 1-12 and found only weak associations between obesity and increased school absences [7]. A national survey in the US of 3470 adolescents reported overweight and obese pupils aged 12-17 years of having 36 and $37 \%$ more sick days, respectively, than their normalweight peers [8]. Among 1387 US children (6-11 years) and 2185 adolescents (12-18 years) a relationship between severe absenteeism and weight status was found only in children but not adolescents [9]. Overweight children were significantly more absent than their normal-weight peers in a US study of 1069 forth to sixth graders [10].

Chronic health conditions like asthma, diabetes or attention deficit hyperactivity disorder (ADHD) lead to higher rates of school absenteeism [11]. The association between children's health and performance in school is undisputable and school absenteeism poses a threat to academic achievement [6].

Additionally, visits to a physician, and productivity losses due to parental absence from the workplace to care for a sick child, mean higher costs for health services and national economies. The aim of this study is to investigate intervention effects of the school-based health promotion program "Join the Healthy Boat" on parameters of direct and indirect medical costs, namely the number of days children missed school because they were sick, their visits to a physician and the number of days a working parent had to stay at home to care for a sick child.

\section{Methods \\ Study description}

As the outcome evaluation of the school-based health promotion program, "Join the Healthy Boat", the BadenWürttemberg Study (BW Study) was conducted all over the state of Baden-Württemberg in southern Germany. The cluster-randomized prospective trial included an intervention group and a wait-list control group. The participating primary schools were used as units for the randomization process. According to the number of classes and grades, six different school types were identified and used as strata for randomization [12]. Randomization was performed on 164 teachers in 91 schools, and resulted in 45 schools in the intervention group and 46 schools in the control group.

The study period covered the academic year 2010/11. Written informed consent was obtained from the parents. The study was registered on the German Clinical Trials Register (DRKS), Freiburg University, Germany, under the DRKS-ID: DRKS00000494. Detailed information on the study protocol has already been published elsewhere [12].

\section{Intervention}

Based on the social cognitive theory [13] and the socioecological model [14], scientists from several disciplines and dedicated practitioners, developed the materials for a health promotion program for all four grades of primary school (age group 6-10), following the intervention mapping approach [15]. The "Join the Healthy Boat" program provides teachers in primary school with various materials to integrate into the regular curriculum without the need for additional lessons. Materials include suggestions for 
classroom and homework activities, active breaks, and material for parental involvement. The program aims at a reduction of screen media use and intake of sugar sweetened beverages on the one hand, and at an increase in physical activity on the other hand. Significant results were found for subgroups of the intervention group for screen media use and tendencies but no significant differences for physical activity and the consumption of sugar sweetened beverages [16]. To ensure a state-wide implementation of the program, 32 experienced teachers from all over Baden-Württemberg were trained in two seminars in the concept and materials ("train-the-trainer"). In turn, they trained teachers in their region ("peer-to-peer") in three vocational training sessions, to secure an appropriate application of the program in their classes.

\section{Participants}

All pupils within first and second grade classes of teachers who registered for the training on the program in the academic year 2010/11 were eligible for participation. Parents of 1968 pupils gave their written informed consent. Figure 1 shows a flow chart with the respective available numbers of pupils and datasets at the different

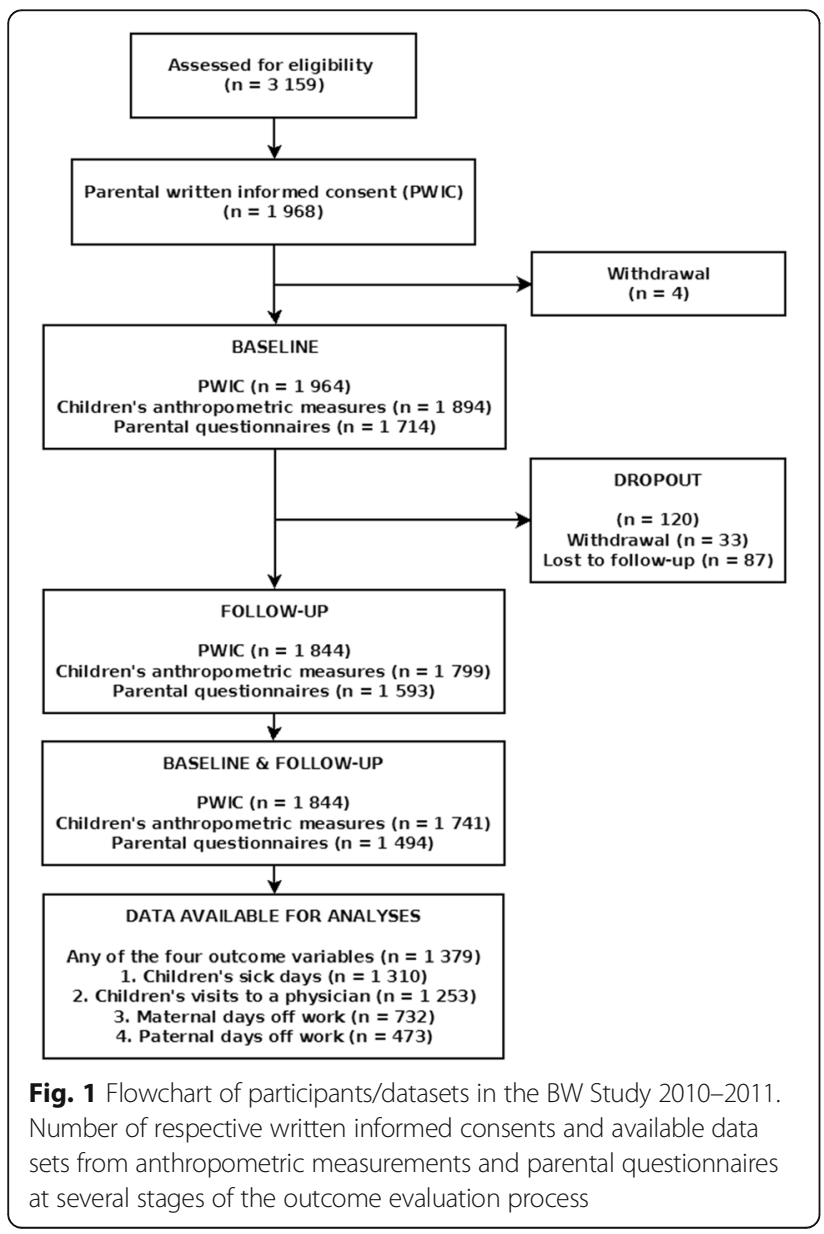

stages of the study. Data for baseline characteristics were available for 1943 pupils. Datasets with longitudinal information about any of the outcome variables sick days of children, visits to a physician and parental days off work were available for 1379 children (71\%).

\section{Data collection}

Baseline data collection was conducted at the beginning of the academic year 2010/11, follow-up measurements took place after a one year intervention period in fall 2011. Four teams of scientific researchers and specially trained students visited each participating class in schools all over Baden-Württemberg, and among others carried out anthropometric measurements and fitness testing of children. Parental questionnaires were handed out by teachers and returned to the data centre.

\section{Anthropometrics and fitness testing}

The weight and height of children were taken by trained staff according to the International Society for the Advancement of Kinanthropometry (ISAK) standards [17]. Waist circumference (WC) was measured midway between children's ileac crest and lower costal arch to the nearest $0.1 \mathrm{~cm}$. Body Mass Index (BMI) was calculated through dividing weight in kilogram by height in square meter $\left(\mathrm{kg} / \mathrm{m}^{2}\right)$, and was converted to BMI percentiles (BMIPERC) using German reference data for children [18]. Excess weight and obesity were accordingly defined at or above the $90^{\text {th }}$ and $97^{\text {th }}$ age- and gender-adjusted percentile for children, respectively. Waist-to-height ratio (WHtR) was calculated as the ratio of WC and height, each of them in centimetres. Abdominal obesity was defined as a WHtR $\geq 0.5$ following the recommendation of McCarthy and Ashwell [19]. A six minute run test was conducted and used as a proxy for cardiorespiratory fitness [20].

Parental BMI and WHtR were calculated according to self-reported weight, height and WC in the questionnaires, and categorized as overweight $(\mathrm{BMI} \geq 25)$, obese $(\mathrm{BMI} \geq 30)$, and abdominally obese (WHtR $\geq 0.5)$.

\section{Questionnaires and derived variables}

Parents were asked to recall the sick days of their children in the last year of school or kindergarten and their children's numbers of visits to a physician during this period (see Table 1). They gave information about their employment status and their weekly working hours, the monthly household income and the number of days they could not go to work because they had to care for their sick child. Furthermore, both parents gave information on their educational level. They were asked to report their height, weight and $\mathrm{WC}$, and to state their current smoker status. Additionally, single parenthood was assessed. 
Table 1 Items in the parental questionnaires for the outcome variables in the BW Study 2010

\begin{tabular}{lll}
\hline Outcome variable & Question & $\begin{array}{l}\text { Response options } \\
\text { (free text) }\end{array}$ \\
\hline Child's sick days & $\begin{array}{l}\text { On how many days during the last year of school or kindergarten was } \\
\text { your child unable to go to school/kindergarten because they were sick? }\end{array}$ & Number of days \\
Visits to a physician & $\begin{array}{l}\text { How often during the last year of school or kindergarten did you have } \\
\text { to visit a physician because your child was sick? }\end{array}$ & Number of visits to a physician \\
Days off work mother/father & If you are employed: On how many days during the last year of school & Father: number of days Mother: \\
& or kindergarten did you have to stay off work because your child was sick? & number of days
\end{tabular}

A migration background of the child was assumed if at least one parent was born abroad or at least one parent mainly spoke a foreign language during the child's first years of life. As parameters of children's health behaviour, their daily time of outdoor play, the number of days per week they met the WHO guideline of moderate to vigorous physical activity (MVPA) of more than $60 \mathrm{~min}$ per day [21], their amount of screen media consumption, their consumption of sugar sweetened beverages, and their breakfast habits were assessed.

Family educational level was ranked in accordance with the CASMIN classification system as the highest level of two parents or the level of a single parent [22]. It was dichotomized for analysis into tertiary level, versus primary and secondary level. Monthly household income was grouped into a low $(<€ 1750)$ and a high ( $\geq € 1750$ ) category. Outdoor playing was dichotomized at above $60 \mathrm{~min} /$ day. Reaching the WHO Guideline for MVPA on four days and more a week was compared to reaching it on three days or less. The use of screen media was divided into more than $60 \mathrm{~min} /$ day or less, and the consumption of sugar sweetened beverages into more than one time per week or less. Having breakfast was divided into "never", and "rarely" vs. "often", and "every day".

\section{Losses to follow-up, missing data}

Losses to follow-up and missing data are common problems in observational trials and may bias the results [23]. Therefore, baseline differences between participants who took part in both measurements and those who were lost to follow-up or had missing outcome variables were examined with the appropriate statistical tests as described below.

\section{Statistical analysis}

Differences between groups were tested according to the scale level and the underlying distribution and variance of the respective variable with Fisher's exact test for categorical data, the Mann-Whitney $U$-test, $t$-test or Welch test for continuous data. Significance level was set to $\alpha<.05$ for two-sided tests. Sample sizes in the analyses differ because of missing data.
Intraclass correlation coefficients (ICC) were calculated for all outcome variables to quantify a possible clustering of data in schools. Intervention effects on the outcome variables were examined in linear regression models or linear mixed models, the latter with respect to a clustering effect. All variables from Table 2, except for the four outcome variables themselves, were considered as possible influential factors on the outcome variables and therefore included in the process of stepwise linear regression analyses. Baseline-differences were tested for their influence on the outcome in regression analyses, and all reported results from regression analyses were adjusted for the baseline values of the outcome. Descriptive and bivariate statistics were conducted with IBM SPSS Release 21.0 for Windows (SPSS Inc, Chicago, IL, USA). Linear regression models as well as linear mixed models were calculated with the statistical software package $\mathrm{R}$ Release 3.1.2 for Windows (http://cran.r-project.org).

\section{Results}

Baseline characteristics

Baseline characteristics for both groups are displayed in Table 2. Differences between intervention and control group were found in the number of children with a migration background, which was significantly higher in the intervention group. Both parents of children in the intervention group had more days off work to care for a sick child than those in the control groups. Furthermore, children in the intervention group played outside less often and reached a slightly lower distance in the six minute run test.

\section{Intervention effects}

Data for the longitudinal changes in the outcome variables are shown in Table 3. In total, a decrease appeared in all four variables over the study period of one year. Significant differences occurred in the number of days children missed at school because of sickness and in the number of maternal days off work in favour of the intervention group. Figure 2 visualises these changes.

Children in the intervention group had a significantly higher reduction in sick days. This effect remains stable for children in grade 1 after adjustment for sex, migration 
Table 2 Baseline characteristics of participants in the BW Study 2010

\begin{tabular}{|c|c|c|c|c|}
\hline & $\begin{array}{l}\text { Missing } \\
\text { Values }\end{array}$ & $\begin{array}{l}\text { Intervention } \\
(n=1072)\end{array}$ & $\begin{array}{l}\text { Control } \\
(n=871)\end{array}$ & $\begin{array}{l}\text { Total } \\
(n=1943)\end{array}$ \\
\hline Boys, n (\%) & & $536(50.0)$ & $459(52.7)$ & $995(51.2)$ \\
\hline Age, years [m (sd)] & & $7.09(0.64)$ & $7.06(0.64)$ & $7.08(0.64)$ \\
\hline Grade 1, n (\%) & & $550(51.3)$ & $474(54.4)$ & $1024(52.7)$ \\
\hline Migration background, n (\%) & 297 & $318(35.1)^{1}$ & $207(28.0)$ & $525(31.9)$ \\
\hline \multicolumn{5}{|l|}{ Anthropometry } \\
\hline BMIPERC, [m (sd)] & 50 & $49.13(28.07)$ & $48.75(27.67)$ & $48.96(27.88)$ \\
\hline Waist circumference, cm [m (sd)] & 54 & $55.72(5.87)$ & $55.41(5.89)$ & $55.58(5.88)$ \\
\hline $\mathrm{WHtR},[\mathrm{m}(\mathrm{sd})]$ & 55 & $0.45(0.04)$ & $0.45(0.04)$ & $0.45(0.04)$ \\
\hline Overweight/obesity, n (\%) & 50 & $107(10.3)$ & $83(9.7)$ & $190(10.0)$ \\
\hline Abdominal obesity, n (\%) & 55 & $90(8.7)$ & $68(8.0)$ & $158(8.4)$ \\
\hline \multicolumn{5}{|l|}{ Parental characteristics } \\
\hline Single parent, n (\%) & 265 & $101(10.9)$ & $76(10.1)$ & $177(10.5)$ \\
\hline Tertiary family educational level, n (\%) & 323 & $293(32.7)$ & $229(31.6)$ & $522(32.2)$ \\
\hline Household income < $1750 € \mathrm{n}(\%)$ & 452 & $113(14.0)$ & $94(13.8)$ & $207(13.9)$ \\
\hline Overweight/obesity (mother), n (\%) & 363 & $279(32.1)$ & $217(30.5)$ & $496(31.4)$ \\
\hline Overweight/obesity (father), n (\%) & 468 & $512(62.3)$ & $386(59.1)$ & $898(60.9)$ \\
\hline Abdominal obesity (mother), $\mathrm{n}(\%)$ & 916 & $275(49.0)$ & $206(44.2)$ & $481(46.8)$ \\
\hline Abdominal obesity (father), n (\%) & 1011 & $386(75.2)$ & $306(73.0)$ & $692(74.2)$ \\
\hline Smoking (mother), n (\%) & 287 & $172(20.7)$ & $175(21.2)$ & $347(21.0)$ \\
\hline Smoking (father), n (\%) & 356 & $234(29.4)$ & $238(30.1)$ & $472(29.7)$ \\
\hline Days off work (mother), median [m (sd)] & $309^{\mathrm{a}}$ & $2[3.09(4.62)]^{2}$ & $0[2.36(4.23)]$ & $1[2.77(4.47)]$ \\
\hline Employed (mother), n (\%) & 302 & $657(72.3)$ & $519(70.9)$ & $1176(71.7)$ \\
\hline Working hours/week (mother), [m (sd)] & $21^{\mathrm{a}}$ & $20.83(10.68)$ & $21.18(11.79)$ & $20.99(11.18)$ \\
\hline Days off work (father), median [m (sd)] & $839^{a}$ & $0[0.78(2.31)]^{2}$ & $0[0.33(1.19)]$ & $0[0.56(1.87)]$ \\
\hline Employed (father), n (\%) & 354 & $833(95.6)$ & $694(96.7)$ & $1527(96.1)$ \\
\hline Working hours/week (father), [m (sd)] & $86^{\mathrm{a}}$ & $43.60(10.65)$ & $43.99(10.35)$ & $43.78(10.51)$ \\
\hline \multicolumn{5}{|l|}{ Health and lifestyle characteristics } \\
\hline Sick days, median [m (sd)] & 390 & $5[7.50(7.70)]$ & $5[6.73(5.97)]$ & $5[7.15(6.97)]$ \\
\hline Visits to a physician, median [m (sd)] & 404 & $2[2.99(2.76)]$ & $2[2.95(3.23)]$ & $2[2.97(2.98)]$ \\
\hline Playing outside > 60 min/day, n (\%) & 296 & $607(66.6)^{3}$ & $523(71.2)$ & $1130(68.6)$ \\
\hline Physical active $\geq 4$ days/week $\geq 60 \mathrm{~min} /$ day, $\mathrm{n}(\%)$ & 320 & $238(26.6)$ & $199(27.3)$ & $437(26.9)$ \\
\hline 6 min run test, meter $[\mathrm{m}(\mathrm{sd})]$ & 63 & $839.67(122.88)^{4}$ & $855.28(120.10)$ & $846.69(121.85)$ \\
\hline Screen media > 1 h/day, n (\%) & 250 & $144(15.4)$ & $100(13.2)$ & $244(14.4)$ \\
\hline Sugar sweetened beverages $>1$ time/week, n (\%) & 241 & $236(25.1)$ & $180(23.6)$ & $416(24.4)$ \\
\hline Skipping breakfast, n (\%) & 236 & $97(12.7)$ & $126(13.4)$ & $223(13.1)$ \\
\hline
\end{tabular}

$m$ mean, $s d$ standard deviation, $W H t R$ Waist-to-height ratio, ${ }^{a}$ with regard to those who stated an employment

${ }^{1} p=0.002,{ }^{2} p<0.001,{ }^{3} p=0.048,{ }^{4} p=0.006$

and baseline values for sick days. First grade children in the intervention and control group had a change of -5.15 vs. -3.64 , respectively, in the numbers of sick days between baseline and follow up, indicating a group difference of 1.51 days $(p=0.02)$. ICC for the differences in sick days was 0.045 (95\% CI $[0.012 ; 0.078])$, thus indicating that $4.5 \%$ of the overall variance was due to the clustering of data in schools. The subsequent analysis in a linear mixed model controlling for data clustering showed no differences in regression coefficients compared to the simple linear regression model; the latter is shown in Table 4.

The difference for maternal days off work lost its significance after adjusting for its baseline values and a random school effect. No intervention effects were found for the paternal days off work and the number of the child's visits to a physician. These results were confirmed 
Table 3 Differences between baseline (2010) and follow-up (2011) in the BW Study

\begin{tabular}{lllll}
\hline & $\begin{array}{l}\text { Missing } \\
\text { values }\end{array}$ & $\begin{array}{l}\text { Intervention } \\
(n=745)\end{array}$ & $\begin{array}{l}\text { Control } \\
(n=634)\end{array}$ & $\begin{array}{l}\text { Total } \\
(n=1379)\end{array}$ \\
\hline Sick days, $m$ (sd) & 69 & $-3.18(7.08)^{1}$ & $-2.31(5.56)$ & $-2.78(6.44)$ \\
Visits to a physician, $m$ (sd) & 126 & $-0.85(2.41)$ & $-0.93(2.70)$ & $-0.88(2.54)$ \\
Days off work (mother), $m(s d)$ & 647 & $-1.11(3.89)^{2}$ & $-0.52(2.84)$ & $-0.85(3.48)$ \\
Days off work (father), $m(s d)$ & 906 & $-0.25(2.21)$ & $0.06(1.56)$ & $-0.10(1.94)$ \\
\hline
\end{tabular}

$m$ mean, $s d$ standard deviation

${ }^{1} p=0.013,{ }^{2} p=0.019$

in linear mixed models adjusted for the respective baseline values and a random school effect.

\section{Losses to follow-up, missing data}

Datasets with any information on the outcome variables $(n=1379)$ were compared to those with completely missing outcome variables $(n=564)$. Those with completely missing outcome variables showed manifold significant baseline differences compared to the others. Lost participants were more likely to be male and to have a migration background; they had larger WC and WHtR and were more often overweight and obese. Their parents were more often single parents, had less often tertiary family education level, and more often a lower household income. Their mothers were more often overweight or obese, both parents were more likely to smoke and mothers were more often unemployed. Children had more sick days in the preceding year of kindergarten or school, they reached shorter distances in the $6 \mathrm{~min}$ run test, were more likely to use screen media for more than one hour per day, consumed more sugar sweetened beverages and were more likely to skip breakfast.

\section{Discussion}

The effectiveness of multicomponent health promotion in a low-threshold approach is not easily determined in

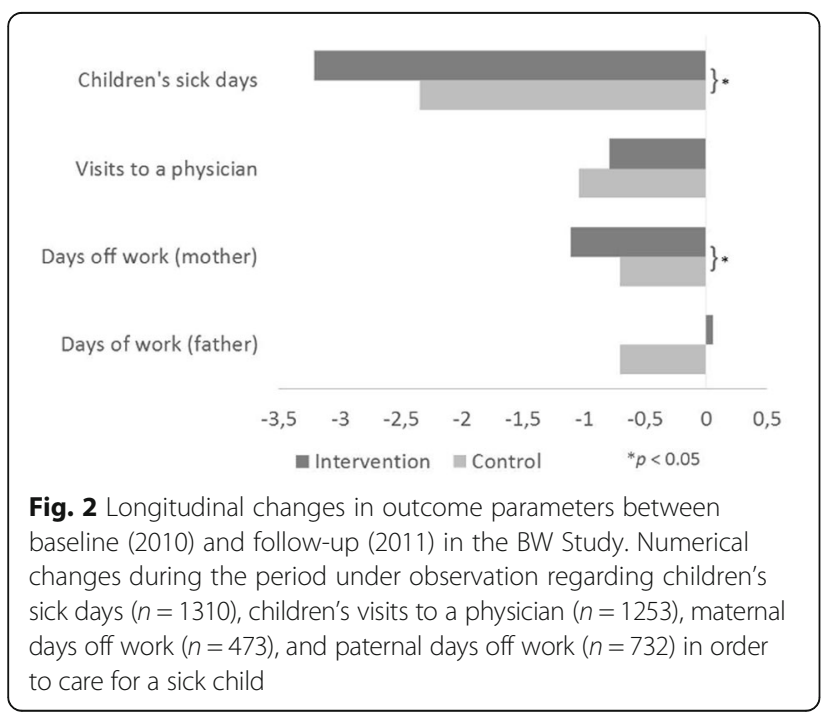

a limited time period. The intervention group shows a stronger downward trend than the control group in all outcome variables except the number of visits to a physician. Only the reduction of sick days in first grade pupils remains statistically significant. This reduction in the number of sick days in the intervention group may result from behavioral changes in physical activity, nutrition, and media consumption, as described by Kobel et al. [16], but also from a reduced incidence in abdominal obesity (unpublished data), which is, as mentioned in the background section, correlated with higher rates of sick days [3]. Although the mean group difference of one sick day seems small for the individual child, this adds up to 550 days for all first grade children in the intervention group, which is a significant number. Small individual effects which benefit the whole group are the typical results of a public health intervention [24].

There is, assumedly, a natural decline in the number of sick days from kindergarten through the first years of primary school, which may at least partly be comprehensible with regard to the natural maturing of the immune system. Furthermore, parents may be more reluctant to keep their children at home as soon as they attend school, rather than they would have been during the time in kindergarten. Nonetheless, a small but statistically significant difference between intervention and control group was detected for the decline in sick days in first grade children. Despite being small, this is an important result for various reasons. Firstly, it shows the positive impact of health promotion on health itself. Secondly, the first year of school may be regarded as crucial with respect to the complete education life-cycle and therefore missing fewer days at school may affect school success.

The missing significance of longitudinal changes in sick days between intervention and control group in grade 2 may have several reasons. First, second grade children and parents are meanwhile familiar with school and the initial enthusiasm and attention to new information has settled and come to a normal extend. This means, school is now day-to-day life for both, parents and children, and they have developed a certain routine. Hence, first grade children (and their parents) may be more susceptible and eager to learn and implement new, alternative behaviours. Second, the decrease of sick days 
Table 4 Results of the linear regression analysis for the change in children's sick days between baseline (2010) and follow-up (2011) in the BW Study

\begin{tabular}{|c|c|c|c|c|c|c|}
\hline \multirow[b]{2}{*}{ Covariate } & \multicolumn{3}{|l|}{ All $(n=1268)$} & \multicolumn{3}{|c|}{ Grade $1(n=654)$} \\
\hline & $B(S E)$ & $\beta$ & $p$-Value & $B(S E)$ & $\beta$ & $p$-Value \\
\hline Intervention & $-0.30(0.22)$ & -0.02 & 0.182 & $-0.83(0.28)$ & -0.06 & 0.003 \\
\hline Grade 1 & $-1.15(0.23)$ & 0.09 & $<0.001$ & & & \\
\hline Female & $0.30(0.22)$ & 0.02 & 0.175 & $0.11(0.28)$ & 0.01 & 0.708 \\
\hline Migration background & $0.49(0.26)$ & 0.03 & 0.060 & $0.59(0.34)$ & 0.04 & 0.085 \\
\hline Sick days baseline value & $-0.74(0.02)$ & 0.77 & $<0.001$ & $-0.78(0.02)$ & 0.83 & $<0.001$ \\
\hline$R^{2}$ & 0.62 & & & 0.69 & & \\
\hline
\end{tabular}

$B$ regression coefficient, $S E$ standard error, $\beta$ standardized regression coefficient

in grade 2 is overall smaller than in grade 1: While at follow-up parents of first graders report 4.5 sick days less in the past year of school, second graders missed just one day less. In both cases the decline was greater in the intervention group, but too small to reach significance in second graders. Therefore, it seems the natural decline is greater during the first year of school and there might be a chance for health promoting interventions to enhance this decline.

We did not find significant differences between intervention and control in the parental days off work in the present study, but the number of days suggests that predominantly mothers stay at home to care for a sick child $(2.8 \pm 4.5$ vs. $0.6 \pm 1.9)$. There may be an association with the fact that mothers report a lower amount of working hours than fathers $(21.0 \pm 11.2$ vs. $43.8 \pm 10.5)$.

Despite no significant difference between groups, children's amount of visits to a physician showed an overall reduction with slightly higher numbers in the control group. This overall reduction can be related to the reduction in children's sick days. If children are less often sick, it seems reasonable that they less often need to see a doctor.

To the authors' knowledge, there is currently little information available in scientific literature with regard to the effect of school-based health promotion on the sickness absence of pupils. In their comprehensive review on cluster-randomized trials for school-based health promotion, Langford et al. reported only two studies on hand hygiene campaigns and their effect on absence rates [25]. Both studies detected significant differences in sickness episodes as well as in the median days of absence in the respective intervention groups [26, 27]. Unfortunately, due to basically different intervention components and differing economic levels of the respective countries [28], outcomes are not comparable to those presented here.

\section{Sick days and correlates}

It is not surprising, that those children with higher numbers of sick days at baseline are more likely to experience a higher reduction. There was no statistically significant effect of a migration background visible in both regression models; although those children often represent a vulnerable group, difficult to reach, and often affected by other unfortunate determinants like higher consumption of sugar sweetened beverages and screen media [29]. In the cross-sectional baseline analysis of sick days, children with a migration background were significantly more likely to have higher rates of absenteeism [3]. Nonetheless, according to the relatively high percentage of children with a migration background in this study (31.9\%), the standardized effect is smaller than expected (0.03). Other research on the effectiveness of the program "Join the Healthy Boat" did not find a migration effect either (unpublished data).

Some authors discuss school absenteeism in the context of obesity, reporting predominantly positive relationships [5-10]. In our baseline analysis we found a significant correlation of sick days with abdominal obesity, children with a WHtR at or above 0.5 were almost twice as likely to have higher rates of absenteeism [3]. In the longitudinal effects of the present health promotion program, no significant association of any obesity measure with sick days was found, but changes in both, abdominal obesity (unpublished data) and sick days as presented here, were affected by the intervention.

Sick leave is undoubtedly hazardous to school success. Baxter et al. found a highly significant inverse relationship between academic achievement and absenteeism in fourth-graders in South-Carolina, USA [6]. In a large study with more than 6000 students aged 14- to 15-years at secondary schools in Iceland, Sigfúsdóttir et al. reported similar associations of absenteeism and academic achievement [30]. Hence, school-based health promotion may have an important impact on school success.

\section{Strengths and limitations}

The present study covers a statewide approach of health promotion in primary schools. Together with the results of the cost-effectiveness analysis (unpublished data), this study shows the effectiveness of this approach, and delivers valuable information for policymakers. According 
to an extensive publication by the WHO "Evaluation in health promotion" among others "suffers from a shortage of evidence on the effectiveness of initiatives" while "funding agencies most commonly require evidence of effectiveness and particularly cost-related effectiveness" [31].

Randomized controlled trials in the field of health promotion are not a general rule, and reviewers always request well-conducted studies of high quality [2, 25]. The strength of the present research lies in its design, plan and conduct as a cluster-randomized, prospective, controlled study based on a publicly available study protocol [12]. Furthermore, the high number of participating schools, classes and pupils, as well as the high return rate of parental questionnaires, contributes to the good quality of this research.

Some sources of bias have to be addressed. Despite an elaborate randomization procedure, some baseline imbalances appeared. This may bias the results and is one of the reasons why baseline-values of the outcome variables were included in the regression analyses in order to minimize the bias. All outcome variables were assessed in questionnaires and were not measured directly and may therefore be subject to recall bias. Parents may not have remembered the exact amount of sick days of their children as well as the exact number of days, one parent had to stay at home to care for a sick child. The same applies to the numbers of visits to a physician. Additionally, there may have been a selection bias on the teacher level as well as on the level of participating parents. Teachers had to opt-in to take part in the program, and parents had to give their written informed consent for participation.

Another inherent problem of this kind of study comprising a wait-list control group is the potential contamination of the control. All teachers who opted-in to take part in the program were asked to take part in the outcome evaluation as well. This means that all participating teachers were highly interested in school-based health promotion. Many of the teachers who were then assigned to the control group may have already included health promotion activities in their teaching routine. Thus, the differences in the outcome measures might be reduced as a result of the contamination.

Studies with an observational character like this one often lack complete data. For this reason, a comprehensive analysis of datasets with missing values and losses to follow-up was conducted. These analyses always show a similar pattern, those participants who are lost for the analysis of effects, are those who would have been of greatest interest. This means, in the present case, children with higher numbers of sick days in the preceding year of the baseline measurements and children with a migration background. It may be assumed that the availability of these datasets for analysis would have strengthened the precision and significance of the results.

\section{Conclusion}

School-based health promotion implemented by teachers within the program "Join the Healthy Boat" has a small but statistically significant impact on the number of sick days in first grade children. This means, participating children in their first grade miss on average one day less because of ill health. Subsequently, parents may not need to stay off work themselves. Small individual effects add up to larger benefits in a statewide implementation of health promotion. Additionally, health promotion may also positively contribute to school success.

\section{Abbreviations}

ADHD: Attention deficit hyperactivity disorder; BMl: Body mass index; BMIPERC: BMI percentiles; BW: Baden-Württemberg; CASMIN: Comparative analysis of social mobility in industrial nations; DRKS: German clinical trials register; ICC: Intraclass correlation coefficient; ISAK: International society for the advancement of Kinanthropometry; MVPA: Moderate to vigorous physical activity; SPSS: Statistical package for the social sciences; WC: Waist circumference; WHO: World Health Organization; WHtR: Waist-to-height ratio

\section{Acknowledgments}

We thank the Baden-Württemberg Stiftung, Stuttgart, State of BadenWürttemberg, Germany and the young scientists program of the German Network Health Services Research Baden-Württemberg for funding this research. The Baden-Württemberg Stiftung and the German Network Health Services Research Baden-Württemberg had no influence on the content of the manuscript.

Thanks to all other members of the "Join the Healthy Boat" research group for their input.

We especially thank Sinéad McLaughlin for her language assistance. Finally and most of all, we thank the teachers, pupils and their parents who participated in the study.

\section{Funding}

"Join the Healthy Boat" was funded by the Baden-Württemberg Stiftung, Stuttgart, State of Baden-Württemberg, Germany. The present research was funded by the young scientists program of the German Network Health Services Research Baden-Württemberg of the Ministry of Science, Research and Arts in collaboration with the Ministry of Employment and Social Order, Family, Women and Senior Citizens, Baden-Württemberg, Germany. The Baden-Württemberg Stiftung and the German Network Health Services Research Baden-Württemberg had no influence on the content of the manuscript.

\section{Availability of data and materials}

The datasets generated and analysed during the current study are not publicly available due to reasons of data protection but are available from the Institute of Epidemiology and Medical Biometry, Ulm University, on reasonable request.

\section{Authors' contributions}

DK and other members of the research group planned and organized the Baden-Württemberg study, and were involved in carrying out the measurements in fall 2010. DK performed the statistical analyses. JMS is the director of the program "Join the Healthy Boat - primary school" and principal investigator of the Baden-Württemberg Study. DK, MT and RL drafted the manuscript. TK and JMS revised the manuscript drafts. All authors have read and approved the final version of the manuscript.

Competing interests

The authors declare that they have no competing interests. 


\section{Consent for publication}

Not applicable.

\section{Ethics approval and consent to participate}

The study protocol was approved by the ethics committee of Ulm University in June 2009 (Application No. 126/10). The Baden-Württemberg Study is registered at the German Clinical Trials Register (DRKS) Freiburg University, Germany, under the DRKS-ID: DRKS00000494. Written informed consent was obtained from parents and teachers.

\section{Author details}

'Division of Sport and Rehabilitation Medicine, Ulm University Medical Center, 89075 Ulm, Germany. ${ }^{2}$ Ulm University, Institute of General Medicine, Helmholtzstraße 20, D-89081 UIm, Germany. ${ }^{3}$ Department of Computer Science, Ulm University of Applied Sciences, 89081 Ulm, Germany.

Received: 31 August 2016 Accepted: 3 December 2016 Published online: 12 December 2016

\section{References}

1. World Health Organization (WHO). School and youth health. 1995. http:// www.who.int/school_youth_health/gshi/en/. Accessed 2 Dec 2015.

2. Stewart-Brown S. What is the evidence on school health promotion in improving health or preventing disease and, specifically, what is the effectiveness of the health promoting schools approach? WHO Regional Office for Europe. Copenhagen. 2006. http://www.euro.who.int/document/ e88185.pdf. Accessed 22 Feb 2016.

3. Kesztyüs D, Wirt T, Kobel S, Schreiber A, Kettner S, Dreyhaupt J, et al. Is central obesity associated with poorer health and health-related quality of life in primary school children? Cross-sectional results from the BadenWuerttemberg Study and The "Komm mit in das gesunde Boot -Grundschule" -Research Group. BMC Public Health. 2013;13:13.

4. Uppal P, Paul P, Sreenivas V. School absenteeism among children and its correlates: a predictive model for identifying absentees. Indian Pediatr. 2010;47:925-9.

5. Wijga AH, Scholtens S, Bemelmans WJE, de Jongste JC, Kerkhof M, Schipper $M$, et al. Comorbidities of obesity in school children: a cross-sectional study in the PIAMA birth cohort. BMC Public Health. 2010;10:184.

6. Baxter SD, Royer JA, Hardin JW, Guinn CH, Devlin CM. The relationship of school absenteeism with body mass index, academic achievement, and socioeconomic status among fourth-grade children. J Sch Health. 2011;81:417-23.

7. Rappaport EB, Daskalakis C, Andrel J. Obesity and other predictors of absenteeism in philadelphia school children. J Sch Health. 2011;81:341-4.

8. Pan L, Sherry B, Park S, Blanck HM. The association of obesity and school absenteeism attributed to illness or injury among adolescents in the United States, 2009. J Adolesc Health. 2013;52:64-9.

9. Li Y, Raychowdhury S, Tedders SH, Lyn R, Lòpez-De Fede A, Zhang J. Association between increased BMI and severe school absenteeism among US children and adolescents: findings from a national survey, 2005-2008. Int J Obes. 2012;36:517-23.

10. Geier A, Foster G, Womble L, McLaughlin J, Borradaile KE, Nachmani J, et al. The relationship between relative weight and school attendance among elementary schoolchildren. Obesity. 2007;15:2157-61.

11. Crump C, Rivera D, London R, Landau M, Erlendson B, Rodriguez E. Chronic health conditions and school performance among children and youth. Ann Epidemiol. 2013;23:179-84. Elsevier Inc.

12. Dreyhaupt J, Koch B, Wirt T, Schreiber A, Brandstetter S, Kesztyues D, et al. Evaluation of a health promotion program in children: Study protocol and design of the cluster-randomized Baden-Wuerttemberg primary school study [DRKS-ID: DRKS00000494]. BMC Public Health. 2012;12:157.

13. Bandura A. Social cognitive theory: an agentic perspective. Annu Rev Psychol. 2001;52:1-26.

14. Bronfenbrenner U. Ökologische Sozialisationsforschung. Ein Bezugsrahmen. [Ecological Socialisation Research. A Reference Framework.]. In: Bauer U, Bittlingmacer $U$, Scherr A, editors. Handbuch Bildungs- und Erziehungssoziologie [Manual Education and Sociology of Education]. Wiesbaden: VS Verlag für Sozialwissenschaften; 2012. p. 167-76.

15. Bartholomew L, Parcel G, Kok G, Gottlieb N. Planning health promotion programs: an intervention mapping approach. 2nd ed. San Francisco: Jossey-Bass; 2006.
16. Kobel S, Wirt T, Schreiber A, Kesztyüs D, Kettner S, Erkelenz N, et al. Intervention effects of a school-based health promotion programme on obesity related behavioural outcomes. J Obes. 2014;2014:476230.

17. Stewart A, Marfell-Jones M, Olds T, Al. E. International standards for anthropometric assessment. Low Hutt, New Zeal Int Soc Adv Kinanthropometry. 2011;125 f.

18. Kromeyer-Hauschild K, Wabitsch M, Kunze D, Geller F, Geiß HC, Hesse V, et al Perzentile für den Body-mass- Index für das Kindes- und Jugend- alter unter Heranziehung ver- schiedener deutscher Stichproben [Percentiles of bodymass index in children and adolescents evaluated from different regional German studies]. Monatsschrift Kinderheilkd. 2001;149:807-18.

19. McCarthy HD, Ashwell M. A study of central fatness using waist-to-height ratios in UK children and adolescents over two decades supports the simple message-'keep your waist circumference to less than half your height'. Int J Obes. 2006;30:988-92

20. Dordel S, Koch B. Basistests zur Erfassung der motorischen Leistungsfähigkeit von Kindern und Jugendlichen - Manual [Basic Test for the Assessment of Motor Capability in Children and Adolescents - Manual]. http://www.fitnessolympiade.de/Inhalt/manual-dordel-koch-test.pdf. Accessed 15 Jan 2016.

21. World Health Organization (WHO). Global Strategy on Diet, Physical Activity and Health. Information sheet: global recommendations on physical activity for health 5-17 years old. 2011. http://www.who.int/dietphysicalactivity/ publications/recommendations5_17years/en/. Accessed 01 Aug 2016.

22. Brauns H, Steinmann S. Educational reform in France, West-Germany and the United Kingdom: updating the CASMIN educational classification. ZUMA Nachrichten. 1999:23:7-44.

23. Vandenbroucke JP, Von Elm E, Altman DG, Gøtzsche PC, Mulrow CD, Pocock $\mathrm{SJ}$, et al. Strengthening the reporting of observational studies in epidemiology (STROBE): explanation and elaboration. PLoS Med. 2007:4:1628-54.

24. Sorensen G, Emmons K, Hunt MK, Johnston D. Implications of the results of community intervention trials. Annu Rev Public Health. 1998;19:379-416.

25. Langford R, Bonell CP, Jones HE, Pouliou T, Murphy SM, Waters E, et al. The WHO Health Promoting School framework for improving the health and well-being of students and their academic achievement. Cochrane Database Syst Rev. 2014;4:CD008958.

26. Bowen A, Ma H, Ou J, Billhimer W, Long T, Mintz E, et al. a cluster-randomized controlled trial evaluating the effect of a handwashing-promotion program in chinese primary schools. Am Soc Trop Med Hyg. 2007;76:1166-73.

27. Talaat M, Afifi S, Dueger E, El-Ashry N, Marfin A, Kandeel A, et al. Effects of hand hygiene campaigns on incidence of laboratory-confirmed influenza and absenteeism in schoolchildren, Cairo, Egypt. Emerg Infect Dis. 2011;17:619-25.

28. The World Bank. Countries and Economies. The World Bank Group. 2015. Available from: http://data.worldbank.org/country. Accessed 21 Dec 2015.

29. Kobel S, Lämmle C, Wartha O, Kesztyüs D, Wirt T, Steinacker JM. Effects of a randomised controlled school-based health promotion intervention on obesity related behavioral outcomes of children with migration background. J Immigr Minor Health. 2016. doi:10.1007/s10903-016-0460-9.

30. Sigfúsdóttir ID, Kristjánsson ÁL, Allegrante JP. Health behaviour and academic achievement in Icelandic school children. Health Educ Res. 2007;22:70-80.

31. World Health Organization (WHO). Evaluation in health promotion: Principles and perspectives.Rootman I, Goodstadt M, Hyndman B, McQueen D, Potvin L, Springett J, et al., editors. WHO regional publications, European series; No. 92:; 2001. 519-521 p. http://www.euro.who.int/_data/assets/pdf_ file/0007/108934/E73455.pdf. Accessed 15 Dec 2015.

\section{Submit your next manuscript to BioMed Central and we will help you at every step:}

- We accept pre-submission inquiries

- Our selector tool helps you to find the most relevant journal

- We provide round the clock customer support

- Convenient online submission

- Thorough peer review

- Inclusion in PubMed and all major indexing services

- Maximum visibility for your research

Submit your manuscript at www.biomedcentral.com/submit 